\title{
Kinetics of transesterification of Madhuca Indica oil over modified zeolites: biodiesel synthesis
}

\author{
S. R. Pratap ${ }^{1,2}$, S. Z. M. Shamshuddin ${ }^{1,2 *}$, N. Thimmaraju ${ }^{1,2}$, M. Shyamsundar ${ }^{1,2}$ and S. S. Reena ${ }^{1,2}$ \\ ${ }^{1}$ Chemistry Research Laboratory, HMS Institute of Technology, Tumkur, Karnataka, India. \\ ${ }^{2}$ Research and Development Center, Bharathiar University, Coimbatore, India.
}

\begin{abstract}
In this article production of biodiesel from Madhuca indica oil (MI-oil) containing high \% of free fatty acids (FFA) by transesterification process with methanol over basic zeolites such as NaY loaded with $5-25 \% \mathrm{KOH}$ is presented. The zeolites were characterized by PXRD, BET and $\mathrm{CO}_{2}$-TPD methods prior to their catalytic activity studies. Optimization of reaction conditions for transesterification was conducted in order to get highest possible yield of biodiesel. 1HNMR and FTIR analysis confirms the conversion of MI-oil to biodiesel. The physico-chemical properties of MI-biodiesel were found to be comparable with that of the standard biodiesel. The $\mathrm{NaY}$ and $\mathrm{KOH} / \mathrm{NaY}$ zeolites were found to be efficient and reusable catalysts without much loss of their catalytic activity when used for several times in biodiesel production.
\end{abstract}

Keywords: Biodiesel; Madhuca indica; Transesterification; KOH/NaY; Kinetics

\section{Introduction}

Biodiesel is a renewable, non-polluting, biodegradable as well as nontoxic fuel having a high potentiality towards replacement of conventional fuels (Ma and Hanna, 1999; Sharma et al., 2008). In Indian scenario, biodiesel is obtained from oil extractions of non-edible feedstock, as the edible oil is scarce and a significant quantity of edible oil is imported (Fukuda et al., 2001).

Madhuca Indica oil (MI-oil) is one of the less expensive and abundantly available non-edible oil in most of the states of India including Karnataka. The MI trees start bearing seeds from seventh year of planting and seed contain 30-40 percent of fatty oil commonly called Mahua oil (i.e., MI-oil). In Indian context, an estimated annual production of MI-oil is about 181,000 tones (Godignur and Murthy, et al., 2009). As these trees grow mainly in jungle area, uncultivated and waste land, its cultivation has no impact on food production. Since MI-oil is less expensive compared to other vegetable oils, MI-oil was selected for the present study which makes production of biodiesel more economical.

Nowadays, commercial biodiesel is produced from transesterification reaction of vegetable oils using homogenous base catalysts such as $\mathrm{NaOH}$ or $\mathrm{KOH}$, as base catalysts catalyze transesterification reaction of oils faster than acidic catalysts (Freedman et al., 1986). But these homogeneous catalysts have disadvantages such as equipment corrosion, saponification and hydrolysis, disabling recovery and reuse of catalysts, purification of products thereby increasing the biodiesel production expensive (Jitputti and Kitiyanan, 2006; Kim et al., 2004). These problems can be prevented by adopting basic heterogeneous catalysts, which offer many advantages such as easy separation, prevention of side reactions and reusability. Various heterogeneous catalysts have been developed so far to catalyze the transesterification of vegetable oils to produce biodiesel. For instance, anionic clays (Kim et al., 2004), calcium carbonate rock (Leclercq et al., 2001), EST-10 (Suppes et al., 2001), Li/Cao and $\mathrm{Na} / \mathrm{NaOH} /-\mathrm{Al}_{2} \mathrm{O}_{3}$ (Watkins et al., 2004), etc. But these type of catalytic materials are complicated to prepare, expensive and reaction rate is relatively slow which restricts their industrial applications. Therefore, it is highly indeed to find inexpensive as well as more efficient catalytic material for the production of biodiesel for commercial applications. Now a days, there is a drastic change in the growth of heterogeneous catalytic materials like potassium catalysts supported on alumina (Xie et al., 2006) and zeolites (Suppes 
and Dasari, et al., 2004). Zeolites are representative support materials having a number of micro pores on the surface with a large specific area suitable for impregnation of basic metals (Rashtizadeh and Farzaneh, 2010; Noiroj et al., 2009). The zeolite $\mathrm{NaY}$ is extensively used in industry mainly due to its high surface area as well as its large pore openings. Zeolite support and its stability mainly depend on $\mathrm{Si} / \mathrm{Al}$ ratio and its structure (Xu et al., 2006). Also, the stability of the crystal lattice structure of zeolites increases with increase in $\mathrm{Si} / \mathrm{Al}$ ratio which clearly indicates that the zeolite $\mathrm{NaY}$ has higher crystal stability than that of $\mathrm{NaX}$. KOH supported on $\mathrm{NaY}$ zeolite can prevent deactivation of the catalytic material and can act as heterogeneous-like system (Noiroj et al., 2009; Xu et al., 2006 and Ramos et al., 2008). It is also known that the basicity or average oxygen charge increases with increase in Al content of zeolite as well as ionic radius of alkali cation (Barthomeuf et al., 1991). Moreover, the influence of $\mathrm{K}$ ions on $\mathrm{NaY}$ zeolite has been rarely reported, under operating reaction temperatures $<343 \mathrm{~K}$ at lesser reaction time. It is the prime reason behind selecting $\mathrm{KOH} / \mathrm{NaY}$ catalytic system for the synthesis of biodiesel for the present work. Further, to the best of our knowledge no literature on the kinetic studies for the synthesis of biodiesel using MI-oil over $\mathrm{KOH} / \mathrm{NaY}$ is reported. It is estimated that transesterification reaction takes place more than 4000 times faster in the presence of basic catalyst compared to acidic (Formo et al., 1954). Hence, transesterification reaction in presence of basic catalysts was adopted for the present study. In order to obtain highest possible yield of biodiesel, the transesterification reactions were optimized by varying reaction temperature, weight of zeolite, molar ratio and reaction time of the catalysts. A kinetic study was conducted for transesterification reaction by utilizing the data obtained under optimized reaction conditions. Reusability of zeolite catalysts in the biodiesel synthesis was also taken-up.

\section{Material and methods}

\section{Chemicals}

MI oil containing high FFA (7-8\%) was procured from local markets of Tumkur, Karnataka, India. Zeolites in their sodium forms were supplied by Sud-Chemie India Pvt. Limited, Baroda. Other chemicals such as potassium hydroxide and methanol were obtained from LOBA Chemie India Ltd.

\section{Preparation of basic zeolites}

The $\mathrm{KOH} / \mathrm{NaY}$ zeolite was prepared by using the method as reported by Noiroj, et al ( Noiroj et al., 2011). The zeolite $\mathrm{NaY}$ was first dried in an hot air oven at $383 \mathrm{~K}$ for $2 \mathrm{~h}$ to remove any water content absorbed on its surface. Thus obtained zeolite $\mathrm{NaY}$ was impregnated with aqueous $\mathrm{KOH}$ with different $\% \mathrm{KOH}$ loadings (5, 10, 15, 20 and 25). Finally all the impregnated zeolite samples were dried at $383 \mathrm{~K}$ for $24 \mathrm{~h}$ in a hot air oven.

\section{Characterization of zeolites}

The BET (surface area) of basic zeolites was calculated by adsorbing nitrogen using automated adsorption instrument (Micrometrics ASAP 2010 model). All the catalysts were characterized for their surface basicity by $\mathrm{CO}_{2}$-TPD methods (Mayura Analyticals). The PXRD patterns were recorded on Philips X'pert X-ray powder diffractometer using $\mathrm{CuK} \alpha$ radiation $\left(\lambda=1.5418 \quad \mathrm{~A}^{\circ}\right)$ and graphite crystal monochromator.

\section{Catalytic activity studies in biodiesel synthesis}

Process: Base catalyzed transesterification of MI-oil over basic zeolites (to synthesize biodiesel)

Transesterification of MI-oil was carried in a $100 \mathrm{ml}$ RB flask fitted with a water-cooled condenser and a thermometer. Known weights of MI-oil, basic zeolite and methanol were heated on a magnetic stirrer cum heater at a reaction temperature of 328-348 K using oil-bath with continuous stirring in a time period ranging from 20-100 min. After the completion of stipulated reaction time, the catalyst was recovered by the process of filtration, washed with acetone and dried for further use. The filtrate consisting of two liquid phases namely, glycerol-rich phase and biodiesel (methyl ester phase) were obtained. The two phases were separated by using a decantation funnel. Then, biodiesel phase consisting of methyl esters, un-reacted oil, methanol and other impurities were washed with de-ionized hot water for refinement. If any traces of catalyst present in the biodiesel was removed by centrifuge method. Thus obtained biodiesel was analyzed by GC-MS (Hewlett Packard) fitted with a capillary column (HP-624, $30 \mathrm{~m} \times 25 \mu \mathrm{m} \times 0.25 \mu \mathrm{m})$, $\mathrm{H}^{1} \mathrm{NMR}$ spectroscopy (Bruker NMR spectrometer, 400 $\mathrm{MHz}$ ), FTIR analysis (Shimadzu, Spectrophotometer in the range of $800-3750 \mathrm{~cm}^{-1}$ ) and elemental analysis (Thermo scientific organic elemental analyzer).

\section{Results and discussion}

\section{Characterization of zeolites}

The surface area and basicity values of basic zeolites (NaY \& $5-25 \% \mathrm{KOH} / \mathrm{NaY}$ ) are presented in Table I. The surface area of pure $\mathrm{NaY}$ was found to be higher than the surface area of $\mathrm{KOH} / \mathrm{NaY}$. When the $\% \mathrm{KOH}$ on $\mathrm{NaY}$ was increased from $5 \%$ to $25 \%$ the surface area was found to decrease gradually. This decrease in the surface area of $\mathrm{NaY}$ zeolite upon 
Table I. Surface area, basicity and yield (\%) of biodiesel over different zeolites used in the present study

\begin{tabular}{lccc}
\hline Zeolite & BET Surface area $\left(\mathrm{m}^{2} / \mathrm{g}\right)$ & Basicity by $\mathrm{CO}_{2}-\mathrm{TPD}(\mathrm{mmols} / \mathrm{g})$ & Yield $(\%)$ of Biodiesel $* * *$ \\
\hline $\mathrm{NaY}$ & 570.5 & 1.50 & 20.0 \\
$5 \% \mathrm{KOH} / \mathrm{NaY}$ & 522.2 & 2.42 & 78.0 \\
$10 \% \mathrm{KOH} / \mathrm{NaY}$ & 501.2 & 2.61 & 86.0 \\
$15 \% \mathrm{KOH} / \mathrm{NaY}$ & 480.9 & 2.80 & 98.9 \\
$20 \% \mathrm{KOH} / \mathrm{NaY}$ & 370.2 & 2.49 & 88.0 \\
$25 \% \mathrm{KOH} / \mathrm{NaY}$ & 210.6 & 2.36 & 83.0 \\
\hline
\end{tabular}

***[Reaction conditions: Molar ratio of methanol: MI-oil =9:1; amount of catalyst $=0.3 \mathrm{~g}$; reaction time $=60 \mathrm{~min}$; reaction temperature $=338 \mathrm{~K}]$.

incorporation of $\mathrm{KOH}$ from 5 to $25 \%$ can be attributed to the formation of $\mathrm{KOH}$ agglomerates on the surface of $\mathrm{NaY}$ zeolites (Noiroj, et al., 2009).

It was observed that the basicity of pure $\mathrm{NaY}$ was lesser than the basicity of $\mathrm{KOH} / \mathrm{NaY}$. When the $\%$ of $\mathrm{KOH}$ was increased from $5 \%$ to $15 \%$ the basicity of $\mathrm{KOH} / \mathrm{NaY}$ was found to increase. This increase may be attributed to an effective dispersion of basic $\mathrm{KOH}$ molecules on the surface of $\mathrm{NaY}$ zeolite. But, when the percentage of $\mathrm{KOH}$ on $\mathrm{NaY}$ was increased beyond $15 \%$, a decrease in the basicity of $\mathrm{KOH} / \mathrm{NaY}$ was observed which can be due to the formation of multilayers of $\mathrm{KOH}$ on $\mathrm{KOH} / \mathrm{NaY}$ zeolite.

\section{PXRD analysis}

The PXRD patterns of $\mathrm{KOH} / \mathrm{NaY}$ zeolite with different weight $(\%)$ of $\mathrm{KOH}$ loadings are presented in Fig. 1. The morphology of $\mathrm{KOH} / \mathrm{NaY}$ is almost similar to that of pure $\mathrm{NaY}$ zeolite. Moreover, the intensity of XRD peaks decreases with an increase in the loading amount of $\mathrm{KOH}$ from 5 to $25 \%$, indicated by peaks at $6^{\circ}, 10^{\circ}, 12^{\circ}, 13^{\circ}, 14^{\circ}, 16^{\circ}, 17^{\circ}, 18^{\circ}$, $20^{\circ}, 21^{\circ}, 23^{\circ}, 24^{\circ}, 25^{\circ}, 26^{\circ}, 27^{\circ}, 28^{\circ}, 29^{\circ}, 30^{\circ}, 31^{\circ}, 32^{\circ}, 33^{\circ}, 34^{\circ}$, $35^{\circ}, 36^{\circ}, 38^{\circ}, 40^{\circ}, 41^{\circ}, 42^{\circ}, 43^{\circ}, 44^{\circ}, 45^{\circ}$ and $46^{\circ}$. This shows that the loading of $\mathrm{KOH}$ on $\mathrm{NaY}$ has least significant effect on its crystalline structure. It is also reported (Xie et al., 2007) that the loading of $\mathrm{KOH}$ maintains pore structure of $\mathrm{NaY}$ which is essential for its catalytic activity.

Catalytic activity studies of basic zeolites (in the synthesis of biodiesel via transesterification)

Transesterification of MI-oil was carried out with methanol $(\mathrm{MeOH})$ over basic zeolite catalysts (NaY, 5-25\% $\mathrm{KOH} / \mathrm{NaY}$ ) by varying the molar ratio, weight of the catalyst, reaction time \& temperature in order to obtain optimized reaction conditions.

Prior to optimization and kinetic studies, transesterification of MI-oil was carried out in the absence of any catalyst and a negligible yield $(\%)$ of biodiesel $(\sim 6 \%)$ was obtained.

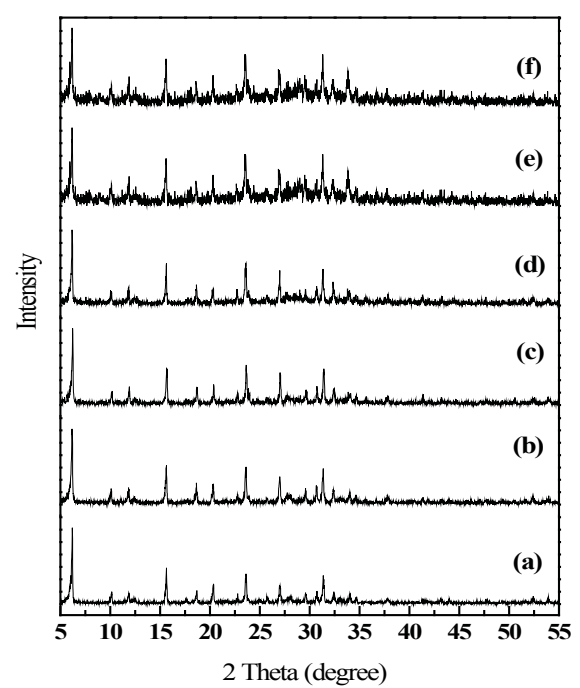

Fig. 1. PXRD patterns of: (a) NaY (b) $5 \% \mathrm{~K} / \mathrm{NaY}$ (c) $10 \% \mathrm{~K} / \mathrm{NaY} \quad$ (d) $15 \% \mathrm{~K} / \mathrm{NaY}$ (e) $20 \% \mathrm{~K} / \mathrm{NaY}$ (f) $25 \% \mathrm{~K} / \mathrm{NaY}$.

Effect of $\mathrm{KOH}$ loading in $\mathrm{KOH} / \mathrm{NaY}$ on the yield (\%) of biodiesel

Effect of wt (\%) of $\mathrm{KOH}$ loading in $\mathrm{KOH} / \mathrm{NaY}$ on the yield (\%) of biodiesel was studied and the results are represented in Fig. 2. 


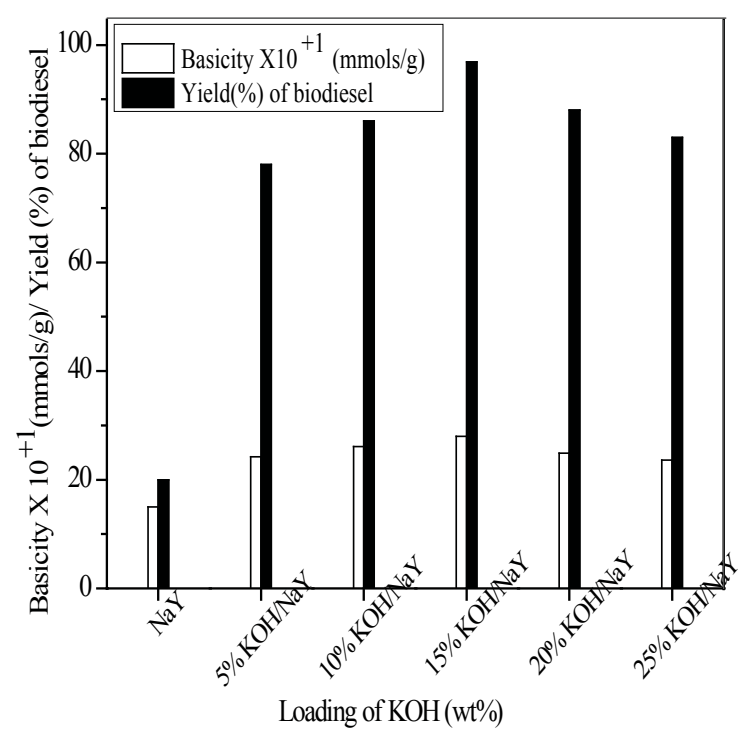

Fig. 2. Yield (\%) biodiesel v/s basicity of 5-20\% KOH/NaY

Among the basic zeolites pure $\mathrm{NaY}$ showed least activity in the transesterification reaction of MI-oil. A correlation between the catalytic activity and basicity of the basic zeolites was observed, i.e., 15\% KOH/NaY which has highest basicity was found to be highly active in transesterification resulting in $98.9 \%$ yield of biodiesel.

Even though the surface area of $15 \% \mathrm{KOH} / \mathrm{NaY}$ is lower than the surface area of pure $\mathrm{NaY}, 15 \% \mathrm{KOH} / \mathrm{NaY}$ showed good activity in transesterification. This indicates that, it is not the surface area which is determining the catalytic activity of $\mathrm{KOH} / \mathrm{NaY}$ but it is the number of active sites (basic sites) which play an important role in its catalytic activity. i.e., no correlation between the surface area and surface basicity of basic zeolite was observed. But rather a correlation between the basicity and the catalytic activity could be observed. For further optimization studies $15 \% \mathrm{KOH} / \mathrm{NaY}$ was selected as the catalytic material.

Effect of molar ratio of MeOH: MI-oil on the yield (\%) of biodiesel

Effect of molar ratio of MeOH: MI-oil was studied over 15\% $\mathrm{KOH} / \mathrm{NaY}$ zeolite. The molar ratio was varied in the range MeOH: MI-oil $=6: 1$ to $15: 1$.

When the molar ratio (MeOH: oil) was increased, the yield (\%) biodiesel was also increased and the highest yield (98.9\%) was observed over $15 \% \mathrm{KOH} / \mathrm{NaY}$ at a molar ratio of $\mathrm{MeOH}$ : MI-oil of 9:1. Beyond the molar ratio of 9:1, i.e., when the amount of $\mathrm{MeOH}$ was taken in excess no impact on yield (\%) of biodiesel was found.

\section{Effect of weight of the zeolites on the yield (\%) of biodiesel}

Effect of weight of the zeolites catalyst on transesterification reaction of MI-oil was studied over $15 \% \mathrm{KOH} / \mathrm{NaY}$ basic zeolite by varying the weight from 0.1 to $0.5 \mathrm{~g}$.

When the weight of catalyst was increased from 0.1 to $0.3 \mathrm{~g}$, the yield (\%) of biodiesel increased and a maximum yield (98.9\%) was observed over $0.3 \mathrm{~g}$ of $15 \% \mathrm{KOH} / \mathrm{NaY}$. The yield $(\%)$ of biodiesel was found to decrease when the amount of the zeolite was increased beyond $0.3 \mathrm{~g}$. This may be due to improper mixing of reactants (MI-oil and $\mathrm{MeOH}$ ) and catalysts (Kim et al., 2004). Therefore, $0.3 \mathrm{~g}$ was found to be an optimum weight of the catalyst.

\section{Effect of reaction temperature on the yield (\%) of biodiesel}

Transesterification reactions were conducted by varying the reaction temperature from 328 to $348 \mathrm{~K}$ over $15 \% \mathrm{KOH} / \mathrm{NaY}$ zeolites. When the transesterification was carried out at 328 $\mathrm{K}$, the yield $(\%)$ of biodiesel was low because at low temperature, there was no sufficient energy to promote collisions extensively among the reactants. But, the yield (\%) of biodiesel increased when the temperature was increased from $328 \mathrm{~K}$ to $338 \mathrm{~K}$. A maximum yield of biodiesel (98.9\%) was observed at $338 \mathrm{~K}$ over $15 \% \mathrm{KOH} / \mathrm{NaY}$ zeolite. But when the reaction was carried out above $338 \mathrm{~K}$, it leads to a decrease in the biodiesel yield. Therefore, an optimum temperature was found to be $338 \mathrm{~K}$.

\section{Effect of reaction time on the yield (\%) of biodiesel}

Effect of reaction time on transesterification reaction of MI-oil was studied over basic zeolite $(15 \% \mathrm{KOH} / \mathrm{NaY})$ by varying the reaction time from 20-100 $\mathrm{min}$.

The yield (\%) of biodiesel increases when the reaction time was increased from $20 \mathrm{~min}$ to $60 \mathrm{~min}$. However, beyond 60 min not much increase in the yield (\%) biodiesel was observed. Besides, longer reaction time may lead to the reduction of biodiesel because of reversible transesterification reaction results in the loss of esters (Canakcin et al., 2001). Therefore, reaction time of $60 \mathrm{~min}$ was found to be an optimum reaction time for the transesterification to obtain good yield (\%) of biodiesel.

\section{Comparison of physico-chemical properties of MI-biodiesel with conventional diesel}

Fuel properties of MI-biodiesel are tested as per ASTM standards and compared with standard commercial biodiesel and presented in Table III. It is observed from the table that the values are comparable. An important property of 
Table II. Reaction rate constant and energy of activation of basic zeolites (5 to $20 \% \mathrm{KOH} / \mathrm{NaY}$ ) for the synthesis of biodiesel via transesterification of MI-oil with methanol

\begin{tabular}{cccc}
\hline Basic zeolite catalyst & Rate constant $\times$ & $10^{-3} \mathrm{~min}^{-1}$ & $\begin{array}{c}\text { Energy of activation (Ea) } \\
\text { for the formation of } \\
\text { biodiesel }\left(\mathrm{kJ} \mathrm{mol}^{-1}\right)\end{array}$ \\
\hline $5 \% \mathrm{KOH} / \mathrm{NaY}$ & $333 \mathrm{~K}$ & $338 \mathrm{~K}$ & \\
$10 \% \mathrm{KOH} / \mathrm{NaY}$ & 1.38 & 2.5 & 111.2 \\
$15 \% \mathrm{KOH} / \mathrm{NaY}$ & 2.04 & 3.0 & 72.62 \\
$20 \% \mathrm{KOH} / \mathrm{NaY}$ & 1.52 & 2.38 & 39.51 \\
& 2.04 & 2.72 & 53.8
\end{tabular}

Table III. Comparision of physico-chemical properties of MI-Biodiesel, commercial biodiesel and standard biodiesel

\begin{tabular}{|c|c|c|c|}
\hline Parameter & MI -Biodiesel & Commercial biodiesel & Stanadard biodiesel \\
\hline Density at $15{ }^{\circ} \mathrm{C}(\mathrm{g} / \mathrm{cc})$ & 0.85 & 0.844 & 0.872 \\
\hline Kinematic viscosity at $100{ }^{\circ} \mathrm{C}(\mathrm{cSt})$ & 3.5 & - & 1.9 to 6.0 \\
\hline Pour point $\left({ }^{\mathrm{O}} \mathrm{C}\right)$ & 1 & -10 & -15 to 10 \\
\hline Flash point $\left({ }^{\mathrm{O}} \mathrm{C}\right)$ & 121 & 70 & 100 to 170 \\
\hline Acid Value (mg KOH/g) & 0.01 & 0.34 & $>0.80$ \\
\hline Water content $(\%)$ & Nil & 0.02 & 0.05 \\
\hline Ash content (\%) & 0.01 & - & Nil \\
\hline Cetane number & 50 & 52 & 51 \\
\hline Carbon residue (\%wt) & 0.33 & - & 0.80 \\
\hline Heating value $(\mathrm{MJ} / \mathrm{Kg})$ & 39.01 & 40.9 & 40.13 \\
\hline Calorific value (kcal/kg) & 9268 & 10665 & 10020 \\
\hline
\end{tabular}
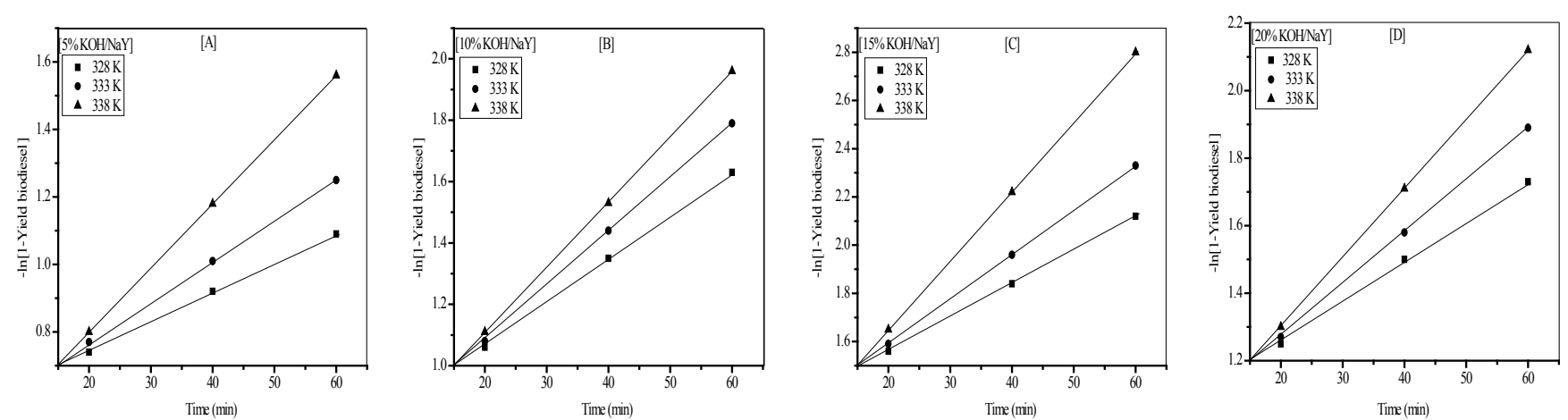

Fig. 3. Plot of first-order rate constants for transesterification reaction of MI-oil over zeolites: (A) $5 \% \mathrm{~K} / \mathrm{NaY}$ (B) $10 \% \mathrm{~K} / \mathrm{NaY}$ (C) $15 \% \mathrm{~K} / \mathrm{NaY}$ and (D) $20 \% \mathrm{~K} / \mathrm{NaY}$ at $328 \mathrm{~K}, 333 \mathrm{~K}$ and $338 \mathrm{~K}$ 


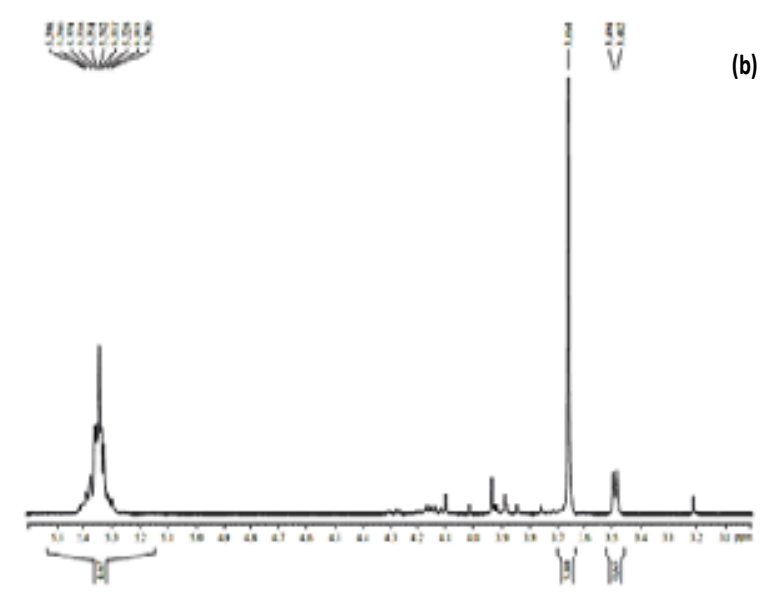

(a)

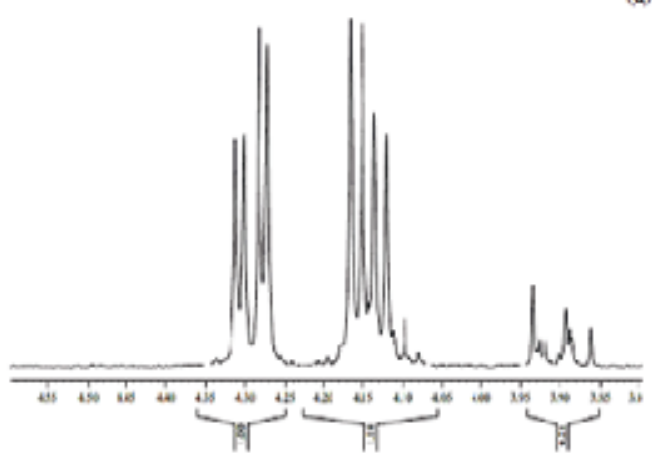

Fig. 4. H $^{1}$ NMR spectra of (A) MI-oil (B) MI-biodiesel

biodiesel is its water content. It has been found that the water content of MI-biodiesel is zero.

\section{Kinetic studies for transesterification (synthesis of biodiesel)}

Kinetic studies were conducted over basic zeolite catalysts $(5-20 \% \mathrm{KOH} / \mathrm{NaY})$. Prior to the kinetic studies, experiments were carried out to establish the effect of mass transfer limitations of transesterification reaction. According to Madon and Boudart (Madon et al., 1982), a linear relationship between the rate of the reaction and weight of the catalyst indicates the absence of all transport limitations.

Plots of $-\ln \left[1-\right.$ yield $\left._{\text {biodiesel }}\right] \quad \mathrm{v} / \mathrm{s}$ reaction time for the transesterification were conducted at different temperatures over basic zeolites $(5,10,15,20 \% \mathrm{KOH} / \mathrm{NaY})$ are shown in Figure 3. (A-D) respectively. The plots are almost linear in all the cases, which indicate that the synthesis of biodiesel via transesterification reaction to be a first-order reaction.

The values of first-order rate constants obtained from the

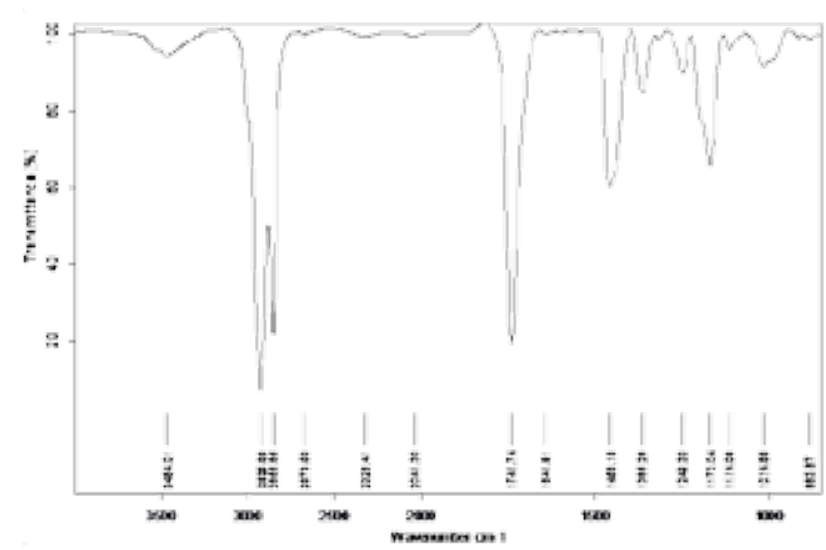

Fig. 5. FTIR spectra of MI-biodiesel

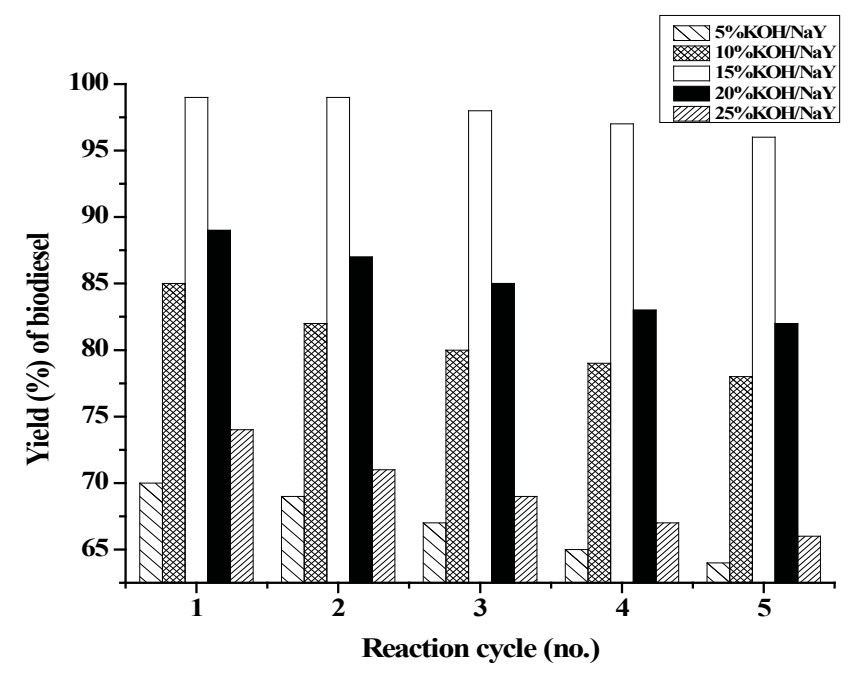

Fig. 6. Reusability of basic zeolites in transesterification of MI-oil

[Reaction conditions: amount of catalyst $=0.3 \mathrm{~g}$; reaction temperature $=338 \mathrm{~K}$; reaction time $=60 \mathrm{~min}$; molar ratio of $\mathrm{MeOH}$ : MI-oil $=9: 1]$.

slopes of the plots and the energy of activation calculated from the Arrhenius equation (Eq. (1)) are presented in Table II. The values of energy of activation of the catalyst for the transesterification were found to be in the order:

$15 \% \mathrm{KOH} / \mathrm{NaY}>20 \% \mathrm{KOH} / \mathrm{NaY}>10 \% \mathrm{KOH} / \mathrm{NaY}>5 \%$ $\mathrm{KOH} / \mathrm{NaY}$

The energy of activation was calculated using Arrhenius equation (Atkins et al., 1988):

$$
E_{a}=2.303 R \log \left(\frac{k_{2}}{k_{1}}\right)\left[\frac{T_{1} X T_{2}}{T_{2}-T_{1}}\right]
$$


where, $\mathrm{R}$, gas constant; $\mathrm{k}_{2}$, rate constant at temperature $\mathrm{T}_{2} ; \mathrm{k}_{1}$, rate constant at temperature $T_{1}$.

Over all the basic zeolite catalysts, $15 \% \mathrm{KOH} / \mathrm{NaY}$ showed lowest $(\mathrm{Ea})$ value indicating that it could be a facile basic catalyst among other basic zeolites used in the present study for biodiesel synthesis.

\section{Analysis of biodiesel}

\section{Using ${ }^{1} H N M R$ technique}

${ }^{1}$ HNMR spetra of crude MI-oil and biodiesel are given in Figure 4. Appearance of a new peak at $3.66 \mathrm{ppm}$ due to $\mathrm{OCH}_{3}$ and disappearance of glyceride protons at $4.0-4.3 \mathrm{ppm}$ in the NMR spectra of biodiesel favours the formation of biodiesel after transesterification of MI- oil.

The purity of biodiesel formed after transesterification can also explained using $\mathrm{H}^{1} \mathrm{NMR}$ by the following methods reported literature (Knoothe et al., 2001).

Biodiesel is a mixture of mono, di, triglycerides associated with glycerol as impurities. In the biodiesel sample, the presence of impurities must be less as specified by EN standards. The absence of peak in the range $3.9-4.5 \mathrm{ppm}$ in ${ }^{1} \mathrm{HNMR}$ spectra of biodiesel after transesterification ruled out the presence of glycerol in the biodiesel sample (Serdarevich et al., 1996).

\section{Using FTIR technique}

FTIR spectrum of MI-biodiesel (Figure 5) shows a carbonyl peak appears at1741.74 $\mathrm{cm}^{-1}$ (Sylvester et al., 2013). The most characteristic peak which represents typical biodiesel (methoxy group $\mathrm{CH}_{3}-\mathrm{O}$ ) appears at $1456.18 \mathrm{~cm}^{-1}$ (Sylvester et al., 2013) and $\mathrm{C}=\mathrm{C}$ double bond absorption appears at 1456.18-1509 $\mathrm{cm}^{-1}$ (Sylvester et al., 2013). Moreover, in the FTIR spectrum of MI-biodiesel, major peaks are observed at $1741.74 \mathrm{~cm}^{-1}, 2855.53 \mathrm{~cm}^{-1}$ and $2925.68 \mathrm{~cm}^{-1}$ respectively.

\section{Elemental analysis of MI-biodiesel}

Elemental analysis was done by using organic thermo scientific elemental analyzer (reactor temperature: $1173 \mathrm{~K}$, Helium \& Oxygen $250 \mathrm{k} \mathrm{Pa}$ each, Flash 2000) and the (\%) elemental contents in biodiesel were found to be carbon (73.90), hydrogen (11.48), oxygen (14.62), nitrogen (0.0) and sulfur (0.0).

\section{Reactivation of basic zeolite catalysts}

Basic zeolite catalysts were recovered from the reaction mixture, washed with methanol and dried over $393 \mathrm{~K}$ for $2 \mathrm{~h}$ and calcined at $923 \mathrm{~K}$ for $1 \mathrm{~h}$ in a muffle furnace before their use in the next consecutive reaction cycle.

Reusability of reactivated basic zeolite catalysts in transesterification

The yield (\%) of biodiesel $\mathrm{v} / \mathrm{s}$ number of reaction cycles was studied over basic zeolites and the results are presented in the Figure 6. All the basic zeolites $(\mathrm{KOH} / \mathrm{NaY})$ used in the present work were found to be effectively reusable for transesterification to synthesize biodiesel at least for 5 reaction cycles.

\section{Conclusion}

In general, zeolites have been found to be effective and facile catalysts in the production of biodiesel from vegetable oils particularly for Madhuca Indica oil. In case of basic zeolites $15 \% \mathrm{KOH} / \mathrm{NaY}$ was found to be a better basic zeolite catalyst with lowest $\mathrm{Ea}(39.51 \mathrm{~kJ} / \mathrm{mol})$ for the synthesis of biodiesel from MI-oil via transesterification. Moreover, basicity of zeolites was found to be correlatable with their catalytic activity. But, no correlation between the surface area of zeolite and their catalytic activity was observed. The conversion of MI-oil to MI-biodiesel was confirmed by ${ }^{1}$ HNMR spectrum and FTIR analysis. The fuel properties of MI-biodiesel were found to be comparable with standard biodiesel as well as commercial biodiesel samples. Furthermore, Elemental analysis shows the absence of sulfur and nitrogen which clearly indicates that the obtained MI-biodiesel is an environmentally benign and eco-friendly biodiesel.

\section{Acknowledgement}

Authors are grateful for the financial support given by VGST, GoK (GRD-375/2014-15). Authors are thankful to IITM, Chennai for TPD analysis and they are also thankful to the authorities of SAIF, IISc Bangalore as well as St. Joseph College, Bangaluru for $\mathrm{H}^{1} \mathrm{NMR}$, FTIR, elemental analysis of biodiesel and PXRD analysis of zeolites respectively.

\section{References}

Atkins PW (1988), Oxford University Press, Oxford, $6^{\text {th }}$ Ed. Physical Chemistry 866.

Barthomeuf D (1991), Acidity and Basicity in zeolites. Stud.Surf. Sci.Catal, 65: 157-169.

Canakcin M, Van Gerpen J (2001), Biodiesel Production from Oils and Fats with High Free Fatty Acids. Transaction of the ASAE 44: 1429-1436. 
Formo W (1954), Ester reactions of fatty materials, J. Am. Oil Chem. Soc, 31(11): 548-559.

Freedman B, Butterfield RO and Pryde EH (1986), Transesterification of kinetics of soyabean oil, J. Am. Oil Chem. Soc, 63: 1375-1380.

Fukuda H, Kondo A and Noda H (2001), Biodiesel fuel production by transesterification of oils, J. Bio Sci.Bio Eng, 92: 405-416.

Godiganur S, Muthy CHS and Reddy RP (2009), 6 BTA 5.9 G 2-1 Cummins engine performance and emission tests using methyl esters of mahua (Madhuca indica) oil/ diesel, Renew Energ, 34: 2172-2177.

Jitputti J, Kitiyanan B, Rangsunvigit P, Bunyakiat K, Attanatho L and Jevanitpanjakul P (2006), Transesterification of crude palm kernel oil and crude coconut oil by different solid catalysts, Chem. Eng. J, 116: 61-66.

Kim HJ, Kang BS, Kim MJ, Park YM, Kim DK, Lee JS and Lee KY (2004), Transesterification of vegetable oil to biodiesel using heterogeneous base catalyst, Catal. Today, 93-95: 315-320.

Knothe (2001), Determining the blend level of mixtures of biodiesel with conventional diesel fuel by fiber optic NIR spectroscopy and ${ }^{1} \mathrm{HNMR}$ spectroscopy, J.Am.Oil Chem.Soc, 78: 10258.

Leclercq E, Finiels A, Moreau C (2001), Transesterification of rapeseed oil in the presence of basic zeolites and related solid catalysts, J. Am. Oil Chem. Soc, 78: 1161-1165.

Madon RJ and Boudart M (1982), Experimental criterian for the Absence of Artifacts in the Measurement of Rates of Heterogeneous Catalytic Reactions. Ind. Eng. Chem. Fundam, 21: 438-447.

Noiroj K, Intarpong P, Luengunaruemitchai A and Samai Jai-in (2009), A comparative study of $\mathrm{KOH} / \mathrm{NaY}$ catalysts for biodiesel production via Transesterification from palm oil, Renew Energy, 34: 1145-1150.

Ramos MJ, Casas A, Rodriguez L, Romero R, Perez A (2008), Transesterification of sunflower oil over zeolites using different metal loading: A case of leaching and agglomeration studies, Appl. Catal. A, 346: $79-85$.
Rashtizadeh E, Farzaneh F and Ghandi M (2010), A comparative study of $\mathrm{KOH}$ loaded on double aluminosillicate layers, micro porous and meso porous material as catalyst for biodiesel production via Transesterification of soyabean oil, Fuel, 89: 3393-3398.

Serdarevich B and Caroll KK (1996), Synthesis and characterization of 1- and 2-monoglycerides of anteiso fatty acids, J. Lipid Res, 7: 277-284.

Sharma YC, Singh B and Upadhyay SN (2008), Advancements in development and characterization of biodiesel: a review, Fuel, 87: 2355-2373.

Suppes GJ, Bockwinke, K, Lucas S, Botts JB, Mason MH, Heppert JA (2001), Calcium carbonate catalyzed alcoholysis of fats and oils, J. Am. Oil Chem. Soc, 78: 139-146.

Suppes GJ, Dasari MA, Doskoci, EJ, Mankidy PJ and Goff MJ (2004), Transesterification of soyabean oil with zeolite and metal catalysts, Appl. Catal. A-Gen, 257: 213-223.

Sylvester O'Donnel I, Demshemino M, Yahaya I and Nwadike, Okoro L (2013), A review on the spectroscopic analysis of biodiesel. European International Journal of Science and Technolgy, 2: 137-146.

Watkins RS, Lee AF and Wilson K (2001), Li-Cao catalysed tri-glyceride transesterification for biodiesel application, Green Chem, 6: 335-340.

Xie W and Li H (2006), Alumina-supported potassium iodide as a heterogeneous catalyst for biodiesel production from soyabean oil, J. Mol. Catal. A, 255: 1-9.

Xie W, Huang X and Li H (2007), Soyabean oil methyl esters preparation using $\mathrm{NaX}$ zeolites loaded with $\mathrm{KOH}$ as a heterogeneous catalyst, Bioresour. Technol, 98: 936-999.

Xu B, Rotunno F, Bordiga S, Prins R and Van Bokhoven JA (2006), Reversibility of structural collapse in zeolite Y: alkaline cracking and characterization, J. Catal, 241: 66-73.

Received: 7 September 2015; Revised: 11 October 2015;

Accepted: 19 October 2015. 